\title{
Cultural Accommodation in Virtual Engineering Academic Teams
}

\section{Mr. Andras Gordon, Pennsylvania State University, University Park}

Andras Gordon is an Instructor of Engineering Design in the School of Engineering Design, Technology and Professional Programs, College of Engineering, The Pennsylvania State University.

Dr. Richard J Schuhmann, Massachusetts Institute of Technology

Dr. Richard F. Devon, Pennsylvania State University, University Park

Mr. Andrew Michael Erdman, The Pennsylvania State University

Dr. Ahmad Atieh, Taibah Univeristy

\begin{abstract}
Ahmad Atieh had received his Ph.D. in Electrical Engineering from University of Ottawa in 1997, M. Sc. from Jordan University of Science and Technology in 1987, and B. SC. degree from Yarmouk University in 1985. His fields of expertise are in optical fiber telecommunication systems, nonlinear optics, optical amplifiers and renewable energy. He worked at the National Research Council of Canada, JDS Uniphase Inc and BTI Systems Inc in Canada. He has over 55 publications and over 20 issued patent and patent pending.
\end{abstract}

\section{Mr. Peter Dietrich, Corvinus University Budapest}

Peter Dietrich is an Instructor at Corvinus University Budapest, Hungary. 


\title{
Cultural Accommodation in Virtual Engineering Academic Teams (CAVEAT)
}

\author{
Mr. Andras Gordon, The Pennsylvania State University \\ Dr. Richard J. Schuhmann, Massachusetts Institute of Technology \\ Dr. Richard F. Devon, The Pennsylvania State University \\ Mr. Andrew M. Erdman, The Pennsylvania State University \\ Dr. Ahmad Atieh, Taibah University, Kingdom of Saudi Arabia \\ Mr. Peter Dietrich, Corvinus University, Hungary
}

\begin{abstract}
Much of the world of engineering has been absorbed by, and is driven by, the global economy. An engineering leadership course has been adapted to capture some of this reality by incorporating globally distributed, virtual teams. The international economy, however, is permeated by a mix of cultures. This paper addresses how cultural influences occur in the global teams, and an experimental method to evaluate intercultural influences is presented. The method is a learning experience for the students and the resulting data are of analytical value to both students and faculty.

Engineering undergraduate students at a university in US worked together with undergraduate students from Europe and the Middle East. These teams were tasked, within an academic semester, to develop conceptual engineering and business solutions for remote customers. Students collaborated with their partners in other countries and with remote customers only by way of electronic media during a semester at the US university. During this period, international student groups experienced the challenges of establishing effective working relationships over long distances and maintaining their teams' cohesion over the duration of the project. Team work can be improved if students learn to appreciate the ways in which the team members' cultural preferences will affect the team's decision-making and performance. An evaluation instrument was developed and it is being tested during the current semester. First, an initial evaluation stage was applied at the beginning of the semester, before students at three universities got to know each other and began their joint project work. At the end of semester, upon conclusion of the project work, students in all three locations will complete a final evaluation stage of the instrument. This pre and post assessment may help them understand how cultural interactions will have influenced team performance during the project, and to what extent they may have been affected through exposure to other worldviews and by responding to the demands of their projects.
\end{abstract}

\section{Introduction and background}

\section{The Need}

Almost all the leading corporations, all the multilateral organizations (UN, World Bank) and many Notfor-Profit organizations (NPOs) are in a great many countries and often in most countries. There are several reasons why global teaming is important to them, summarized below. (Devon \& Bilén, 2014).

Costs: When information travels, people do not. This means saving time and money and avoiding fatigue.

Scale \& Timeline: Because the costs are much less, it is possible to create more, and more active, relationships. This includes meetings with members in more than two locations, and meetings called at short notice. 
Increased Productivity: Virtual teams often see an increase in productivity because of the 24-hour clock. Each distributed team unit around the globe simply picks up where the prior team unit left off. This approach is referred to as "Follow the Sun." This means a faster time to market for new products. Outsourcing, parallel activities may be better than sequential but both are used.

New Markets: Geographically dispersed teams provide access to different global market opportunities. Virtual teaming allows for such distributed teams to integrate their activities and leverage their resources. Cultural and political mistakes are avoided.

New \& Cheaper Resources: such as local markets, natural, human, and industrial resources, and diversity in specific skill sets are the major reasons for global operations that create the need for teaming. (Devon and Bilen, op. cit.) These benefits are enhanced by the use of global teaming which permits the easy exchange of data and the sharing of data on cloud platforms.

Such teams are not the only mechanism for global operations and some travel is inevitable. These visits help establish personal relationships and build trust. They are also far more information rich than virtual teams, including meeting many more people and touring facilities.

This widespread availability of communication technologies and tools makes it possible for geographically dispersed and culturally diverse expert groups to collaborate productively and achieve optimal solutions for non-local clients. However, if organizational needs and information technology make global teaming both necessary and ubiquitous, there is still the question of how to do it effectively. This means becoming adept at managing the inevitable cultural mix in each team that will always be present, and which can be highly variable from team to team.

Increasingly, a cultural mix may also be found in co-located teams. They are becoming quite common, and many countries in the EU, Singapore, and the Middle East have a mix of nationalities in their professional work force. For example, even in the current US class there are students from different countries. But our interest, at present, is in globally dispersed teams with mixed cultures. We believe that understanding how to lead virtual teams is an essential engineering leadership skill, which is why we are doing this in a leadership course.

\section{The Problem}

There are so many cultures that blend and interact in so many ways. We need to have ways to identify what is important in the professional context: what will enhance the work environment and what will bring it to a standstill?

For any given culture there is usually a considerable literature available to provide a deep understanding of that country or region. There is much less scholarship on how to compare different cultures, and almost none on how to blend cultures and manage a mix. Hofstede and Hall identify what Parsons called pattern variables along which cultures vary such as universalism-particularism, masculinityfemininity or individualism-collectivism. We follow this approach here, but our quest is to see if these cultural characteristics affect team dynamics. Lewis writes about the collision of cultures, and this is very relevant to team conflict management. His many examples are fascinating, but for any given team he may or may not have a relevant example. He, too, has a typology that is a triangle of pattern variables in which he places all cultures. In fact, he places countries, but he discusses the issue of sub-cultures in his book. His ideal types are linear-active (Anglo-Saxon), multi-active (Latin), and reactive (East Asian). A rare example of studying the management of mixed cultural teams is that of Ferraro (5th ed, 
2006). He is very familiar with Hofstede, et al. But he does not study virtual teams and he spends a lot of time on expatriates, which is not relevant to us.

As Lewis observes, you have to treat all people personally as individuals and relying on stereotypes may be devastating in a relationship or team. However, there are stereotypical business cultures that operate in various countries to varying extents.

\section{The Course}

A course with real world project assignments was developed at the Pennsylvania State University, in which US undergraduate engineering students currently work together with undergraduate business students at Corvinus University, Hungary and undergraduate engineering students at Taibah University, Saudi Arabia. Bilateral and trilateral international working teams were formed and they are tasked, within an academic semester, to develop conceptual and applied engineering and business solutions for remote customers in various parts of the world, such as private and community businesses, nongovernmental organizations, municipalities. During the semester, international student groups experience the challenges of establishing effective working relationships over long distances and maintaining their team's cohesion over the duration of the projects. While intercultural virtual student teams are eager to advance in their assigned tasks, it is also vital for them to understand the challenges presented by the mix of cultures. For the teams to work effectively, mutual trust and understanding must be developed. Each student in this course works in the confluence of cultural spheres of partners in project teams, faculty as well as clients and sponsors.

Interactions within international teams, with clients and faculty are done during scheduled class sessions and mostly outside of classroom by way of various networking channels. In classroom student teams hold discussions with the aid of industrial quality video conferencing equipment, outside of classroom students are required to maintain their own ways of interacting in project teams through available electronic networking media. Each project team is required to deliver a comprehensive report on results achieved to clients and sponsors at the end of semester.

The post-course student feedback on the value of this collaboration experience is generally positive, but additional enhancement opportunities exist. We hypothesize that we can improve team performance if students learn to understand the ways in which the culture and worldviews of the team members affect the team's decision-making and performance. In fact, when cultural accommodation does not take place one might expect worse team performance in a mixed culture team. This would produce a U shape or "bath tub" performance curve when both cases are included - lots of bad and lots of good results, and not much in the middle. This means students must first understand their own cultural orientation and worldview and how representative it is of their home country, then achieve a similar understanding of the other team members. In this way, students recognize when virtual cross-cultural teams require cultural and personal accommodation and integration in order to accomplish the tasks at hand. This is a global leadership skill, and developing this skill requires metrics of culture and worldviews.

\section{The Method}

An experimental evaluation instrument was developed, in form of a pre and post collaboration questionnaires, based in part on the well-regarded approaches by G. Hofstede, R. Lewis and E. Hall. Interpretations of cultures in terms of what we have, what we do, and how we think (Gary Ferraro, The 
Cultural Dimensions of International Business, 2005, Prentice Hall) are also integrated.

G. Hofstede studied questionnaires received from employees at IBM branches across the world and used data from 40 countries in order to define a suite of national cultural indices (Geert Hofstede, Cultures and Organizations: Software of the Mind, 2010). Hofstede initially defined four bipolar dimensions and later added an additional two dimensions. According to Hofstede, the four fundamental "mental (software) programs" we assimilate early in life are a function of our cultural environment and consist of four primary cultural dimensions: (1) Power Distance; (2) Individualism; (3) Masculinity; (4) Uncertainty avoidance. The (PDI) reflects how equally power is distributed in a society, (INV) indicates how people view themselves within a society as individuals or part of a collective, MAS reflects the degree to which a society values competition, UAI measures the comfort level with unknowns and a proclivity for risk-taking. M. Minkov (2007) using data from the World Values Survey developed the (5) Long Term versus Short Term Orientation, then Hofstede \& Minkov (2010) added the (6) Indulgence versus Restraint dimensions (Dimensionalizing Cultures: The Hofstede Model in Context, 2011).

Hofstede's "national division" approach to cultural classification is criticized by some. B. McSweeney (2002) challenges underlying data assumptions, suggesting weaknesses with respect to Hofstede's interview data, suggesting that IBM employees are unique and not representative of the average population within the studied subsidiary nation, and that cultural diversity within national boundaries makes this type of analysis unproductive (McSweeny, B., Hofstede's model of national cultural differences and their consequences: A triumph of faith - a failure of analysis, (2002), Human Relations, Volume 55(1): 89-118).

M. Jones (2007) also critiques the notion of national homogeneity, adding that the study, however valuable it may once have been, may now be outdated and possessing too few dimensions with which to quantify contemporary cross-cultural dynamics.

While Humans are an amalgam of human nature, age, culture and personal experience, and as such must be treated, and valued, as individuals, for the purpose of this paper, we place value on Hofstede's and other's work in helping students develop abstractions with which to understand behavior when they observe it. But whereas Hofstede was interested in the countries as dependent variables and cultural metrics as independent variables (how does country vary by culture), we are interested in team performance metrics as dependent variables and cultural metrics as independent variables (how does team performance vary by culture). So, while we clearly have different nationalities in our sample, they are of interest only as a source of different cultures. We are not trying to generalize about Hungary, Saudi Arabia, or the United States, and we clearly do not have the sampling in place to do that even if we had that objective.

Cultures can be viewed in a number of other ways, including based upon communication styles. People communicate relying either upon an explicit vernacular where little is assumed, or using deeper contextimplicit meanings and non-verbal cues. E. Hall defined literal communication as low context; communication with implicit meaning as high context (E. Hall, 1977). Low context communication assumes information is delivered verbally and relies heavily upon content; uncertainties in low context communication represent communication flaws requiring further clarification. High context communication is influenced by social hierarchy and requires listeners to read between the lines; the speaker is also allowed a means by which to save face in the event of a conflict. 
R. Lewis categorizes nations' axes of activities. Cultures are either linear in their approach (e.g. strict chronologically sequential scheduling), multi-actives (e.g. scheduling by interest), and reactive (e.g. courtesy and respect for authority influencing their actions), or somewhere in between (Lewis, R.D., When Cultures Collide, 3rd Edition, 2005, Brealey Publishing).

The instrument developed leveraged aspects of Hofstede's national "personalities", Hall's "communication styles", and Lewis's "work approach". Nine typical situations were formulated in a generic way that individuals can recognize in their personal lives. Five questions expressed the four bipolar Hofstede and one Minkov dimensions, four questions were based on Hall's communication and Lewis's activities categories. The question statements are presented in form of five-level Likert items.

The initial stage of the instrument was applied at the beginning of the semester, before students at three universities got to know each other and began their joint project work. At the end of semester, upon conclusion of their international project work, students in all three locations will complete the final evaluation stage. The surveys are administered on hard copy medium in each of three locations independently, data collection from surveys is done under special research protocol for human subjects, personal identification of participants will be kept confidential in each location.

Collaboration in bilateral and trilateral international teams is done in English language. Students with English learned as foreign language in these groups are mostly fluent enough to pursue the technical objectives of assigned project tasks, however it is known that the uneven proficiency in English can be an impediment in nuanced communication. The concepts presented in questionnaires are meant to express personal attitudes assimilated by individuals early in life in native language environments. With this in mind, it was important that English survey questionnaires were translated into Hungarian and Arabic languages and independently reviewed by bilingual speakers. This approach with survey languages is supported, for example, by B. Sebastian Reiche, IESE Business School, University of Navarra and Anne-Wil Harzing, University of Melbourne (2007).

The first application of the questionnaire is designed to measure the importance of the expressed nine situations for each student individually, based on their prior personal life experience. The second application is meant to measure how often students contemplate about the same nine situations in the course of international collaboration in virtual teams during the semester.

It is expected that with the first questionnaire students managed to clarify for themselves deep personal attitudes, preferences, convictions in defined typical situations. We hypothesize that under the influence of collaboration with culturally different partners for about two and a half months during the semester, via electronic media only, students' answers in the second questionnaire will reveal some of their experiences that could come from actual teamwork dynamics and project outcomes, understood to be related to certain differences and conflicts in cultural attitudes in defined typical situations. Results of two surveys will be compared for individuals and teams. It remains to be seen if any meaningful correlations will be found between questionnaire results and students' opinions about their experiences.

An extension to the two stage evaluation instrument is also under consideration. This will be a postcollaboration reflections assignment for each student upon completion of project work at the end of current semester. Students will be requested to reflect on what are the most important cultural influences that in their views have impacted their international team work and project outcomes. 


\section{Data Analyses, Results and Discussion}

At the time of submission of this paper the first survey has already been completed in all three locations and data are being collected. The second survey and a possible extension in some form of postcollaboration reflections by students will be administered at the end of current semester. Results of first and second surveys will be compared in context of students' reflections on their experiences and project work results. A post-collaborative analysis will be done in order to see if and how international teams' performance characteristics will be observed to be dependent on cultural influences.

\section{Conclusions}

It is well known that in international collaboration situations we have to be mindful of various stereotypical business cultures. It is most important to realize that in order to be successful in collaborative endeavors one has to appreciate participants as individuals and learn to accommodate to cultural peculiarities. This is especially challenging when interactions between individuals are possible only by means of electronic communications. In the present study we attempt to observe this process in

a dedicated engineering leadership course, together with associated courses at two other universities in culturally very diverse countries. We hope that the applied evaluation procedure will bring about valuable insights for students in all three countries and will be useful for improving these courses in the future. In the meantime, the students are sensitized to the role of cultural influences without focusing on specific national cultures.

\section{References:}

1. The Cultural Dimensions of International Business, Gary Ferraro, Prentice Hall, 2005

2. Cultures and Organizations: Software of the Mind, Gert Hofstede, 2010

3. Dimensionalizing Cultures: The Hofstede Model in Context, Geert Hofstede, Online Readings in Psychology and Culture, Unit 2 Theoretical and Methodological Issues, Subunit 1 Conceptual Issues in Psychology and Culture, Article 8, 2011

4. Hofstede's model of national cultural differences and their consequences: A triumph of faith - a failure of analysis, McSweeny, B., Human Relations, Volume 55(1): 89-118), 2002

5. Hofstede - Culturally questionable? Jones M., Oxford Business \& Economics Conference. Oxford, UK, 24-26 June, 2007

6. When Cultures Collide, Lewis, R.D, 3rd Edition, Brealey Publishing, 2005

7. Beyond Culture, Edward T. Hall, Anchor Books, 1977 
8. Unpacking the Concept of Virtuality: The Effects of Geographic Dispersion, Electronic Dependence, Dynamic Structure, and National Diversity on Team Innovation, Cristina B. Gibson, Jennifer L. Gibb, Administrative Science Quarterly, 51 (2006): 451-495

9. Multi-Cultural Dimensions and Multi-Modal Communication in Distributed, Cross-Disciplinary Teamwork, Renate Fruchter, Alicia Townsend, Int. J. Engineering Ed. Vol. 19, No. 1, pp. 53-61, 2003

10. Toward an Understanding of Culture and the Performance of Teams in Complex Systems, Allan Hodgson, Ella-Mae Hubbard, and Carys E. Siemieniuch, IEEE Systems Journal, Vol. 7, No. 4, December 2013

11. Communication Style and Cultural Features in High/Low Context Communication Cultures: A Case Study of Finland, Japan and India, Shoji Nishimura1, Anne Nevgi and Seppo Tella, WebCEF Project Work Package 3: Transcultural Communication (23.5.2009) Partner 6, University of Helsinki

12. Beyond a Literature Review of Hall's Context Dimension: Scale Development, Validation \& Empirical Findings within a Norwegian Study, Gillian Warner-Søderholm, International Journal of Business and Management; Vol. 8, No. 10; 2013

13. Key Issues in International Survey Research - White paper, B. Sebastian Reiche, IESE Business School, University of Navarra, Anne-Wil Harzing, University of Melbourne, 2007

14. Shaping the World: Teaching Global Leadership Skills to Engineers, Richard J. Schuhmann, Sarah Zappe, ASEE Cape Town, South Africa, 2008

15. Teamwork Quality and the Success of Innovative Projects: A Theoretical Concept and Empirical Evidence, Martin Hoegl, Washington State University, Department of Management and Decision Science and Hans Georg Gemuenden, Technical University of Berlin, Chair for Technology and Innovation Management, Organization Science, 2001

16. "Virtual Global Teaming", An overview, Richard Devon, Sven Bilen, the Pennsylvania State University, ScribD, March 2014. 